\title{
Prognostic role of podocalyxin-like protein expression in various cancers: A systematic review and meta-analysis
}

\author{
Jing Wang ${ }^{1, *}$, Yongzhao Zhao ${ }^{2, *}$, Ruizhao $\mathrm{Qi}^{{ }^{3, *},}$ Xiaoning Zhu ${ }^{1}$, Chenshen Huang ${ }^{2}$, \\ Sijin Cheng ${ }^{2}$, Shengzhi Wang ${ }^{3}$ and Xiaolong $\mathbf{Q i}^{1}$ \\ ${ }^{1}$ Department of Hepatobiliary Disease, Affiliated Traditional Chinese Medicine Hospital, Southwest Medical University, \\ Luzhou, China \\ ${ }^{2}$ School of Medicine, Tongji University, Shanghai, China \\ ${ }^{3}$ Department of General Surgery, 302 Hospital of PLA, Beijing, China \\ *These authors have contributed equally to this work \\ Correspondence to: Yongzhao Zhao, email: yongzhao_zhao@163.com \\ Shengzhi Wang, email: 994233529@qq.com
}

Keywords: prognostic, podocalyxin-like protein, cancer, overall survival

Received: October 19,2016 Accepted: November 20, $2016 \quad$ Published: December 25, 2016

Copyright: Wang et al. This is an open-access article distributed under the terms of the Creative Commons Attribution License 3.0 (CC BY 3.0), which permits unrestricted use, distribution, and reproduction in any medium, provided the original author and source are credited.

\section{ABSTRACT}

Several studies were conducted to explore the prognostic significance of podocalyxin-like protein (PODXL) expression in various cancers, with contradictory. This study aims to summarize the prognostic significance of PODXL expression in cancers. PubMed, the Cochrane Library and Embase were completely retrieved. The prospective or retrospective studies focusing on the prognostic role of PODXL expression in cancers were eligible. The endpoints were overall survival (OS), diseasespecific survival (DSS) and disease-free survival (DFS).12 studies involving a total of 5,309 patients were identified. The results indicated that high PODXL expression was significantly associated with worse OS when compared to the low PODXL expression $\left(\mathrm{HR}=1.76,95 \% \mathrm{CI}=1.53-2.04, \mathrm{p}<0.00001 ; \mathrm{I}^{2}=41 \%, p=0.08\right)$. And similar results were detected in the subgroup analysis of analysis model, ethnicity, sample size, tumor type and antibody type. And the results also showed that high PODXL expression was obviously related to shorter DSS $\left(H R=2.47,95 \% C I=1.53-3.99, p=0.0002 ; I^{2}=66 \%\right.$, $p=0.03)$ and DFS (HR=2.12, 95\%CI =1.58-2.85, $\left.\mathrm{p}<0.00001 ; \mathrm{I}^{2}=19 \%, p=0.29\right)$. In conclusion, it was revealed that high PODXL expression is an unfavorable predictor of OS, DSS and DFS in patients with cancers, and high PODXL expression is a promising prognostic biomarker for cancers, especially for patients in European.

\section{INTRODUCTION}

Podocalyxin-like protein (PODXL), an important transmembrane glycoprotein belonging to the CD34 family [1], is usually expressed on the apical surface of podocytes and glomerular epithelial cells [2]. However, it also expressed by breast epithelium [3], vascular [4] and haematopoietic progenitors [5]. The main function of PODXL was regulating the cell morphology and adhesion by the connections between the intracellular proteins and extracellular ligands [6-8].

Recently, several studies indicated that PODXL might be a predictor of prognosis in various cancers, such as colorectal cancer (CRC) [9-12], pancreatic cancer (PC) [13-15], glioma [16], esophageal and gastric adenocarcinoma (EGAC) [17, 18], urothelial bladder cancer (UBC) [19], breast cancer (BC) [20] and so on. The role of PODXL in tumorigenesis remains unclear, but it has been demonstrated to promote the tumor growth, invasion and metastasis [21, 22].

Although it was reported that PODXL expression might be associated with prognostic outcomes in patients with cancers, the dispute does exist. The study conducted by the Larsson et al 2016 showed that high PODXL expression predicted worse overall survival (OS) in CRC when compared with the low PODXL expression 
in cohort II, however, no significant correlation between the PODXL expression and OS was observed in cohort III [11]. Chijiiwa et al covered that high PODXL expression was obviously related to the shorter disease free survival (DFS) in PC [14], but Forse et al reported that high PODXL expression was a favorable factor of prognosis in BC [20]. Besides the study conducted by Heby et al presented that high PODXL expression was evidently associated with worse recurrence-free survival (RFS) in cohort I. Nevertheless, no significant relationship was detected in patients in cohort II [13]. In view of the controversy, the systematic review and meta-analysis was performed to explore the prognostic role of PODXL expression in various cancers.

\section{RESULTS}

\section{Literature search}

As shown in Figure 1, a total of 382 papers were identified and 46 duplicative papers were excluded. As for the remaining 336 papers, 312 were excluded by scanning the titles or abstracts. For the 24 potentially associated studies remained, the full-texts were carefully read. Among these 24 studies, 4 were excluded for insufficient datum to assess the HR of prognosis outcomes, and 7 were excluded for not focusing on the topic, and 1 were excluded because the included patients were covered in the other one study. At last, 12 studies involved 5,309 patients were eligible for this meta-analysis [9-20].

\section{Characteristics of included studies}

As listed in Table 1, the twelve included studies contained sixteen cohorts involving 5,309 patients [9-20]. The percentage of males in the included studies varied from $46.0 \%$ to $77.2 \%$. And the sample size was also different, varying from 70 patients to 775 patients. In term of ethnicity, nine studies focused on the European [9-13, 15, 17-19], one study focused on the Asian [14] and two studies focused on the North American [16, 20]. As for survival analysis, nine studies reported the OS [9-11, 13-16, 18, 19], four studies covered the DSS or CSS [9, $12,17,19]$, two studies reported the TTR $[10,18]$, three studies reported the DFS [10, 14, 20], one study covered the PFS [19], and one study reported the RFS [13]. In addition, four studies focused on the prognostic role of PODXL in CRC [9-12], one study focused on the glioma [16], one focused on the UBC [19], one paid attention to the BC [20], three focused on the PC [13-15], and two studies focused on the prognostic role of PODXL in EGAC $[17,18]$. It must be said that three studies conducted by Larsson et al respectively focused on the same cohorts [9-11]. Besides, the HRs of prognosis were assessed with multivariate analysis in ten studies [9-13, $15,17-20]$, while assessed with univariate analysis in the other two studies $[14,16]$. Moreover, six studies used the polyclonal antibody to stain the PODXL [9-11, 13, 18, 19], one studies used the monoclonal antibody [14] and three studies used both polyclonal antibody and monoclonal antibody $[12,15,17]$ but two studies did not report the antibody type $[16,20]$.

\section{Meta-analysis of OS}

Seven studies containing eleven cohorts were included into the pooled analysis. As shown in Figure 2, no obvious heterogeneity was detected $\left(\mathrm{I}^{2}=41 \%, p=0.08\right)$, and fixed-effect model was used. The results presented that PODXL expression was distinctly associated with the $\mathrm{OS}(\mathrm{HR}=1.76,95 \% \mathrm{CI}=1.53-2.04, p<0.00001)$, which indicated that high PODXL expression predicted worse OS compared to the low PODXL expression. In additions, the influence analysis was carried out and no decisive effect of included studies was observed (Supplementary Figure $\mathrm{S} 1$ ), and no significant bias among all included studies was detected by funnel plot (Supplementary Figure S2).

To explore the source of heterogeneity, the subgroup analysis of OS was conducted. As listed in Table 2 , regarding the analysis model of included studies, it was shown that high PODXL expression was significantly correlated with the shorter OS when the included studies were assessed with multivariate analysis model $(\mathrm{HR}=1.67$, $\left.95 \% \mathrm{CI}=1.40-1.99, p<0.00001 ; \mathrm{I}^{2}=48 \%, p=0.05\right)$, using fixed-effect model. And similar results were detected when the included studies were assessed with univariate analysis $(\mathrm{HR}=1.97,95 \% \mathrm{CI}=1.54-2.52, p<0.00001)$, with no heterogeneity $\left(\mathrm{I}^{2}=0 \%, p=0.54\right)$. In terms of ethnicity, the results demonstrated that high PODXL expression was an unfavorable prognostic factor in cancers in European $\quad(\mathrm{HR}=1.67,95 \% \mathrm{CI}=1.40-1.99, \quad p<0.00001$; $\left.\mathrm{I}^{2}=48 \%, \quad p=0.05\right)$, in North American $(\mathrm{HR}=1.92$, $95 \% \mathrm{CI}=1.48-2.49, p<0.00001)$ and in Asian $(\mathrm{HR}=1.51$, $95 \% \mathrm{CI}=1.12-5.62, p=0.03)$. As for the subgroup analysis of sample size, PODXL expression was obviously related to the OS in patients with cancers both when sample size $<300\left(\mathrm{HR}=1.88,95 \% \mathrm{CI}=1.50-2.36, p<0.00001 ; \mathrm{I}^{2}=39 \%\right.$, $p=0.13)$ and $\geq 300(\mathrm{HR}=1.62,95 \% \mathrm{CI}=1.20-2.18, p=0.002$; $\left.\mathrm{I}^{2}=54 \%, p=0.09\right)$. With respect to tumor type, evident correlation between the PODXL expression and OS was observed. High PODXL expression might increase 35\% risk of death compared with the low PODXL expression in $\mathrm{CRC}\left(\mathrm{HR}=1.35,95 \% \mathrm{CI}=1.01-1.80, p=0.04 ; \mathrm{I}^{2}=9 \%\right.$, $p=0.33$ ), using fixed-effect model. And it was also shown that high PODXL expression was an adverse predictor of $\mathrm{OS}$ in patients with $\mathrm{UBC}(\mathrm{HR}=2.14,95 \% \mathrm{CI}=1.47$ $\left.3.10, p<0.0001 ; \mathrm{I}^{2}=0 \%, p=0.88\right)$. Similar results were observed in $\mathrm{PC}(\mathrm{HR}=2.12,95 \% \mathrm{CI}=1.18-3.83, p=0.01$; $\left.\mathrm{I}^{2}=69 \%, p=0.02\right)$ and EGAC $(\mathrm{HR}=2.03,95 \% \mathrm{CI}=1.04-$ $3.96, p=0.04)$. Moreover, the results presented that high PODXL expression was distinctly associated with worse $\mathrm{OS}$ in patients with glioma $(\mathrm{HR}=1.92,95 \% \mathrm{CI}=1.48$ $2.49, p<0.00001)$. In the subgroup analysis of polyclonal antibody, the high PODXL expression was evidently 
Table 1: Characteristics of included studies

\begin{tabular}{|c|c|c|c|c|c|c|c|c|c|}
\hline Study & Year & Country & Ethnicity & Patients (n) & Male (\%) & Outcome & Tumor & Analysis & Antibody \\
\hline $\begin{array}{l}\text { Larsson et al } \\
2011 \text { [9] }\end{array}$ & 2011 & Sweden & European & 536 & 47.9 & OS, CSS & CRC & M & $\mathrm{P}$ \\
\hline $\begin{array}{l}\text { Larsson et al } \\
2012[10]\end{array}$ & 2012 & Sweden & European & 576 & 50.3 & $\begin{array}{l}\text { OS, TTR, } \\
\text { DFS }\end{array}$ & CRC & M & $\mathrm{P}$ \\
\hline $\begin{array}{l}\text { Binder et al } \\
2013[16]\end{array}$ & 2013 & USA & $\begin{array}{c}\text { North } \\
\text { American }\end{array}$ & 342 & NR & OS & Glioma & $\mathrm{U}$ & NR \\
\hline $\begin{array}{l}\text { Boman et al } \\
2013 \text { (1) [19] }\end{array}$ & 2013 & Sweden & European & 100 & 74.0 & $\mathrm{OS} \uparrow$ & UBC & M & $\mathrm{P}$ \\
\hline $\begin{array}{l}\text { Boman et al } \\
2013 \text { (2) [19] }\end{array}$ & 2013 & Sweden & European & 343 & 75.8 & $\begin{array}{l}\mathrm{OS} \uparrow, \mathrm{DSS}, \\
\text { PFS } \int\end{array}$ & UBC & M & $\mathrm{P}$ \\
\hline $\begin{array}{l}\text { Forse et al } \\
2013 \text { [20] }\end{array}$ & 2013 & Canada & $\begin{array}{c}\text { North } \\
\text { American }\end{array}$ & 698 & 0.0 & DFS & $\mathrm{BC}$ & M & NR \\
\hline $\begin{array}{l}\text { Kaprio et al } \\
2014[12]\end{array}$ & 2014 & Finland & European & 775 & 45.0 & DSS & CRC & M & $\mathrm{P}, \mathrm{Mo}$ \\
\hline $\begin{array}{l}\text { Heby et al } \\
2015 \text { (1) [13] }\end{array}$ & 2015 & Sweden & European & 63 & 46.0 & $\mathrm{RFS} \dagger, \mathrm{OS} \dagger$ & PAC & M & $\mathrm{P}$ \\
\hline $\begin{array}{l}\text { Heby et al } \\
2015 \text { (2) [13] }\end{array}$ & 2015 & Sweden & European & 107 & 53.2 & RFS $\uparrow, \mathrm{OS}_{\dagger} \dagger$ & PPC & M & $\mathrm{P}$ \\
\hline $\begin{array}{l}\text { Laitinen et al } \\
2015 \text { [17] }\end{array}$ & 2015 & Finland & European & 266 & 51.5 & DSS & GC & M & P, Mo \\
\hline $\begin{array}{l}\text { Borg et al } \\
2016[18]\end{array}$ & 2016 & Sweden & European & 171 & 77.2 & TTR, OS & EGAC & M & $\mathrm{P}$ \\
\hline $\begin{array}{l}\text { Chijiiwa et } \\
\text { al } 2016[14]\end{array}$ & 2016 & Japan & Asian & 70 & NR & DFS, OS & $\mathrm{PC}$ & $\mathrm{U}$ & Mo \\
\hline $\begin{array}{l}\text { Larsson et al } \\
2016 \text { (1) [11] }\end{array}$ & 2016 & Sweden & European & 533 & 47.3 & OS & $\mathrm{CRC}$ & M & $\mathrm{P}$ \\
\hline $\begin{array}{l}\text { Larsson et al } \\
2016(2)[11]\end{array}$ & 2016 & Sweden & European & 259 & 49.0 & OS & CRC & M & $\mathrm{P}$ \\
\hline $\begin{array}{l}\text { Larsson et al } \\
2016 \text { (3) [11] }\end{array}$ & 2016 & Sweden & European & 310 & 49.0 & OS & $\mathrm{CRC}$ & M & $\mathrm{P}$ \\
\hline $\begin{array}{l}\text { Saukkonen } \\
\text { et al } 2015 \\
{[15]}\end{array}$ & 2015 & Finland & European & 168 & NR & OS & PDAC & M & P, Mo \\
\hline
\end{tabular}

OS, overall survival; CSS, cancer-specific survival; TTR, time to recurrence; DFS, disease free survival; DSS, diseasespecific survival; PFS, progression-free survival; RFS, recurrence-free survival; $\dagger$, 5 years; $\int, 2$ years; M, multivariate analysis; U, univariate analysis. CRC, colorectal cancer; UBC, urothelial bladder cancer; PC, pancreatic cancer; EGAC; $\mathrm{BC}$, breast cancer. NR, not reporting. P, polyclonal antibody; Mo, monoclonal antibody. 
related to shorter OS in cancers, using fixed-effect model $\left(\mathrm{HR}=1.67, \quad 95 \% \mathrm{CI}=1.40-1.99, \quad p<0.00001 ; \quad \mathrm{I}^{2}=48 \%\right.$, $p=0.05)$, and similar result was detected in the subgroup analysis of monoclonal antibody $(\mathrm{HR}=2.13,95 \% \mathrm{CI}=1.46$ $\left.3.11, p<0.0001 ; \mathrm{I}^{2}=0 \%, p=0.65\right)$.

\section{Meta-analysis of DSS}

Four studies reported the DSS or CSS and were enrolled into the meta-analysis of DSS. As shown in Figure 3 , in view of the obvious heterogeneity $\left(\mathrm{I}^{2}=66 \%\right.$, $p=0.03$ ), the random-effect model was applied. And the results indicated that high PODXL expression was evidently correlated with the shorter DSS in cancers $(\mathrm{HR}=2.47,95 \% \mathrm{CI}=1.53-3.99, p=0.0002)$. Besides, no decisive effect was observed according to the influence analysis (Supplementary Figure S3), and no significant bias among all included studies was detected by funnel plot (Supplementary Figure S4).

\section{Meta-analysis of DFS}

Two studies reported the TTR, three studies reported the DFS, one study reported the PFS and two studies reported the RFS. However, the study conducted by Forse et al was excluded for the apparent increase of heterogeneity $\left(\mathrm{I}^{2}=19 \%\right.$ and $\mathrm{I}^{2}=76 \%$, respectively). The study conducted ty the Larsson et al 2012 both covered the TTR and DFS, and the DFS was extracted and enrolled into the meta-analysis. Therefore, five studies including six cohorts were included into the meta-analysis of DFS. As shown in Figure 4, there was no obvious heterogeneity among the included studies $\left(\mathrm{I}^{2}=19 \%, p=0.29\right)$. It was shown that high PODXL expression predicted shorter DFS when compared with the low PODXL expression in various cancers $(\mathrm{HR}=2.12$, $95 \% \mathrm{CI}=1.58-2.85, p<0.00001)$. In additions, no decisive effect was observed according to the influence analysis (Supplementary Figure S5), and no publication bias among all the included studies was detected by funnel plot (Supplementary Figure S6).

\section{DISCUSSION}

Increasing evidences showed that PODXL expression was associated with prognosis in various cancers [9-20]. Furthermore, plenty of studies

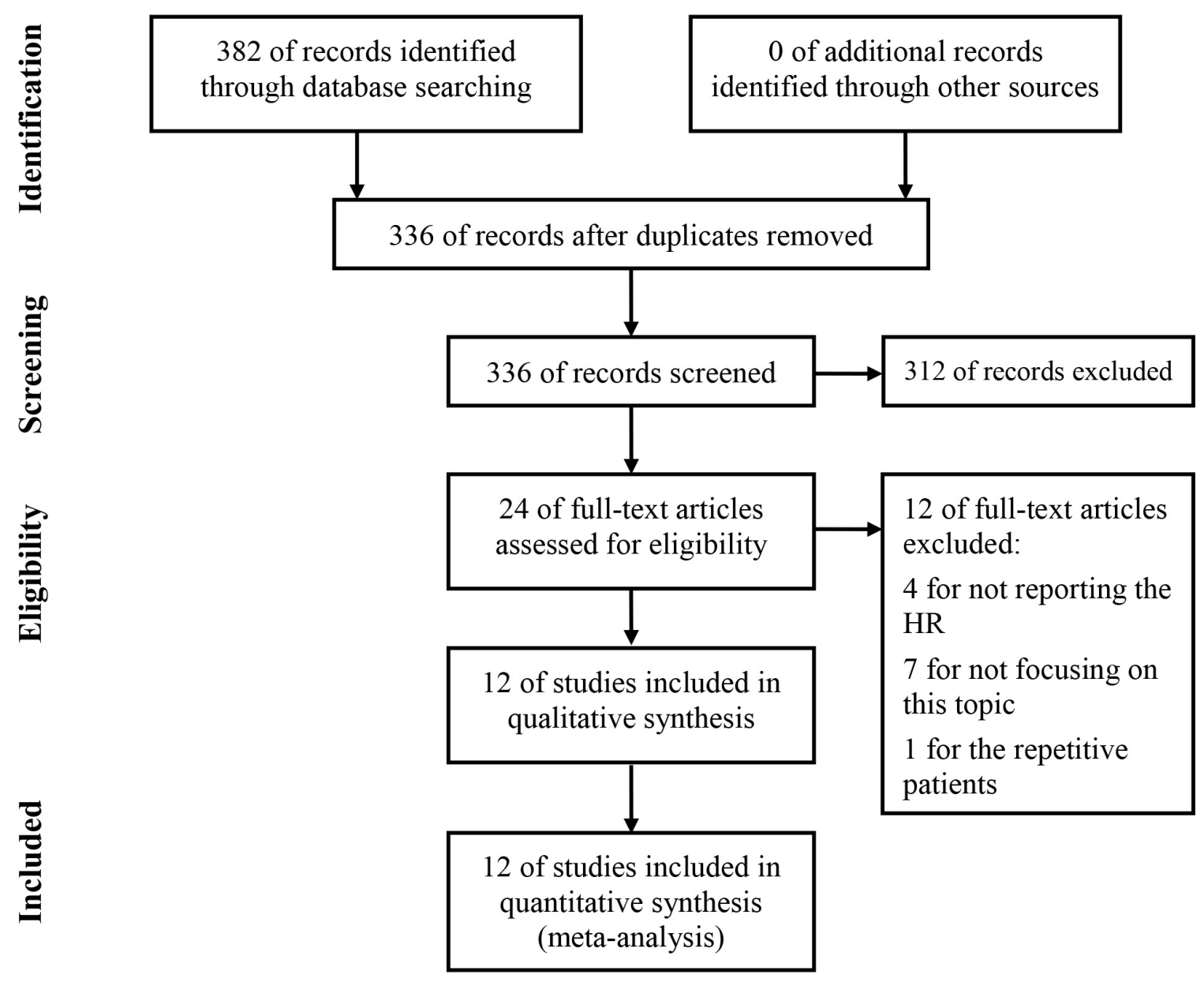

Figure 1: Flow diagram of study selection process. 
demonstrated that PODXL played a key role in the formation of primary tumors growth and metastasis [21, 22]. And Lin et al covered that PODXL might promote tumor formation and metastasis by activating the Rac1/ Cdc42/cortactin signaling [23]. Thomas et al reported that PODXL is an E-/L-selectin ligand on colon carcinoma cells [7]. Therefore, more and more researchers focused on the role of PODXL in cancers. Nevertheless, the prognostic role of PODXL expression in cancers was controversial.

In our study, the results showed that high PODXL expression was significantly associated with worse OS compared with the low PODXL expression. And similar results were detected in the subgroup analysis of analysis model, ethnicity, sample size, tumor type and antibody type. The high PODXL expression was still obviously correlated with shorter OS when all the included studies were assessed with the multivariate analysis, which made the conclusion more convincing. It was also indicated that the correlation between the PODXL expression and OS remained distinct in European. Although similar results were observed both in Asian and North American, the results were short of reliability for the limited included studies. Therefore, to further explore the relationship between the PODXL expression and prognosis of cancers in Asian and North American, more relevant studies should be put into effect in Asian and North American. As for the sample size, the relationship between the PODXL expression and OS was distinct both when sample size $\geq 300$ and $<300$, which further confirmed the prognostic role of PODXL in various cancers. The results also showed that high PODXL expression predicted shorter OS in multiple tumors, especially in PC and CRC. In additions, although the Larsson et al 2016 covered that no obvious correlation between the high PODXL expression and OS was observed in cohort I [11], which was inconsistent with the previous study [9], it was remained convincing for more patients assessed with multivariate analysis [11]. Besides, the antibody type influenced the prognostic role of PODXL expression in various cancers. In the study conducted by Kaprio et al, it was declared that high PODXL expression was an unfavorable predictor in CRC, and the patients with high PODXL expression predicted worst OS when the PODXL was stained by combined polyclonal antibody and monoclonal antibody [12]. Similarly, in the Laitinen et al study, the association between the PODXL expression and OS remained significant in multivariable analysis only when the polyclonal antibody was used [17]. Therefore, more prospective studies should be carried out to explore the antibody use in the immunohistochemical of PODXL.

As for the DSS, our study indicated that high PODXL expression predicted worse DSS when compared to the low PODXL expression. Combining the OS, the high PODXL expression became a promising predictor of prognosis in cancers and should be paid more attention to. In additions, it was revealed that PODXL expression was obviously associated with DFS, and high PODXL expression predicted worse DFS compared with the low PODXL expression. However, it should be noted that all the included studies in the meta-analysis of DSS was conducted in European, and main included studies in the pooled analysis of DFS also focused on the European. Therefore, the conclusion should be used cautiously in Asian. And more studies should be payed attention to the prognostic role of PODXL expression in cancers in Asian.

The highlighted strength of our study as follows: First, to the best knowledge of us, the study was the first systematic review and meta-analysis to explore the prognostic role of PODXL expression in various cancers, and the results contributed to the development of the research concerning the prognostic role of PODXL in cancers. Second, twelve studies with a relatively large population were finally included, hence, the results were convincing. Third, the comprehensive subgroup analyses were carried out, such as ethnicity, antibody type, tumor type and so on. Fourth, no obvious heterogeneity was observed in the meta-analysis of OS and DFS, therefore, the pooled effects were accurate.

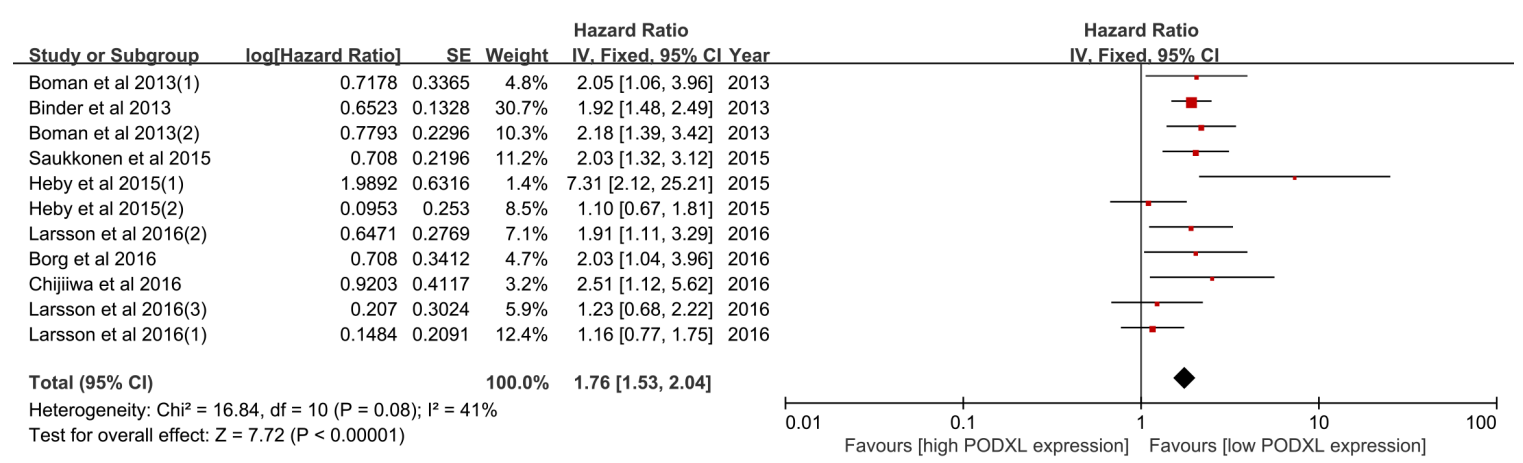

Figure 2: Meta-analysis of overall survival. 
Table 2: Subgroup analysis of overall survival

\begin{tabular}{|c|c|c|c|c|c|}
\hline Survival analysis & Included cohorts & HR 95\% CI & $p$ & $\mathbf{I}^{2}$ & $\begin{array}{c}p \text { value for } \\
\text { heterogeneity }\end{array}$ \\
\hline \multicolumn{6}{|l|}{ Analysis model } \\
\hline Multivariate & 9 & $1.67[1.40,1.99]$ & $<0.00001 \ddagger$ & $48 \%$ & 0.05 \\
\hline Univariate & 2 & $1.97[1.54,2.52]$ & $<0.00001 \ddagger$ & $0 \%$ & 0.54 \\
\hline \multicolumn{6}{|l|}{ Ethnicity } \\
\hline European & 9 & $1.67[1.40,1.99]$ & $<0.00001 \ddagger$ & $48 \%$ & 0.05 \\
\hline North American & 1 & $1.92[1.48,2.49]$ & $<0.00001 \$$ & NA & NA \\
\hline Asian & 1 & $1.51[1.12,5.62]$ & $0.03+$ & NA & NA \\
\hline \multicolumn{6}{|l|}{ Sample Size } \\
\hline$<300$ & 7 & $1.88[1.50,2.36]$ & $<0.00001 \ddagger$ & $39 \%$ & 0.13 \\
\hline$\geq 300$ & 4 & $1.62[1.20,2.18]$ & $0.002 \%$ & $54 \%$ & 0.09 \\
\hline \multicolumn{6}{|l|}{ Tumor } \\
\hline $\mathrm{CRC}$ & 3 & $1.35[1.01,1.80]$ & $0.04 \dagger$ & $9 \%$ & 0.33 \\
\hline UBC & 2 & $2.14[1.47,3.10]$ & $<0.0001 \ddagger$ & $0 \%$ & 0.88 \\
\hline $\mathrm{PC}$ & 4 & $2.12[1.18,3.83]$ & $0.01 \ddagger$ & $69 \%$ & 0.02 \\
\hline EGAC & 1 & $2.03[1.04,3.96]$ & $0.04 \dagger$ & NA & NA \\
\hline Glioma & 1 & $1.92[1.48,2.49]$ & $<0.00001 \$$ & NA & NA \\
\hline \multicolumn{6}{|l|}{ Antibody } \\
\hline $\begin{array}{l}\text { Polyclonal } \\
\text { antibody }\end{array}$ & 9 & $1.67[1.40,1.99]$ & $<0.00001 \$$ & $48 \%$ & 0.005 \\
\hline $\begin{array}{l}\text { Monoclonal } \\
\text { antibody }\end{array}$ & 2 & $2.13[1.46,3.11]$ & $<0.0001 \ddagger$ & $0 \%$ & 0.65 \\
\hline
\end{tabular}

OS, overall survival; NA, not applicable; CRC, colorectal cancer; UBC, urothelial bladder cancer; PC, pancreatic cancer; EGAC, esophageal and gastric adenocarcinoma; $p<0.05$, the difference was significant.

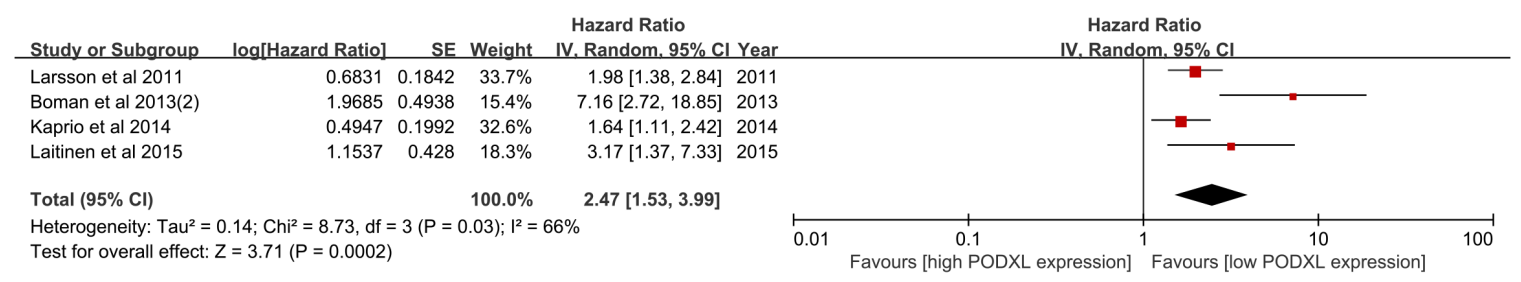

Figure 3: Meta-analysis of disease-specific survival.

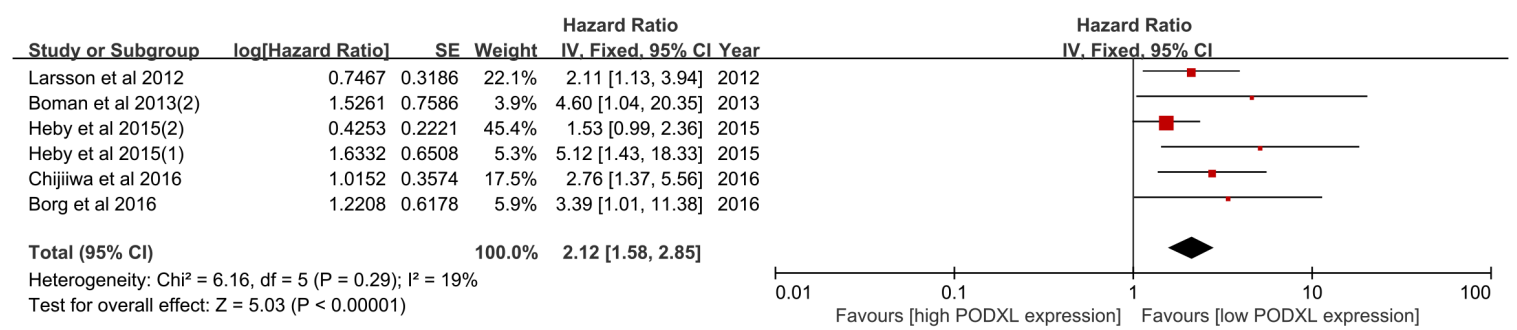

Figure 4: Meta-analysis of disease free survival. 
Furthermore, several limitations of our study should be carefully considered. First, the conclusion of some tumors should be used with caution for the limited included studies, such as BC, glioma and so on. Second, the data was obtained from the published articles, so the individual data was unavailable. Third, the heterogeneity remained significant in the meta-analysis of DSS. And the accuracy of the results might be reduced for the use of random-effect model. Fourth, moderate publication bias might be existed for the reason that the researchers tended to report the positive results.

In conclusion, it was revealed that high PODXL expression is an unfavorable predictor of OS, DSS and DFS in various cancers, and high PODXL expression is a promising prognostic biomarker for cancers, especially for patients in European.

\section{MATERIALS AND METHODS}

\section{Literature search strategy}

PubMed, the Cochrane Library and Embase were comprehensively searched up to October 10, 2016. The search strategy was "((((Tumor) OR Neoplasm) OR Cancer) OR carcinoma) AND (((((podocalyxin-like 1) OR Podocalyxin-like protein) OR PODXL) OR Podocalyxin) OR Podocalyxin-like)". All the retrieved papers were checked. And the reference lists were also checked. The obviously irrelevant articles were excluded by scanning the titles or abstracts. The remaining papers were then reviewed comprehensively by carefully reading the full text.

\section{Inclusion criteria}

The studies meeting all the criteria should be included: 1) prospective or retrospective studies; 2) paying attention on the role of PODXL expression on the prognosis in various cancers; 3 ) enough data to get the hazard ratio (HR) for prognostic outcomes, along with their $95 \%$ confidence intervals (CIs) or $p$ values; 4) studies published in English.

\section{Exclusion criteria}

The exclusion criteria were as follows: 1) neither the prospective nor retrospective studies; 2) studies without enough data to get the HR; 3) studies not focusing on the role of PODXL expression on the prognosis in various cancers; 4) not published in English.

\section{Data extraction}

All the manuscripts were independently reviewed by two investigators (Zhao $\mathrm{Y}$ and Wang J). The following data were carefully abstracted: first name of the first author, year of publication, country of the study, ethnicity, the numbers of patients, percentage of males, tumor type, survival outcomes, analysis model and antibody type. The HRs of prognostic outcomes obtained directly or indirectly from published articles were integrated in the meta-analysis according to the study conducted by Tierney et al [24]. If the multivariate analysis and univariate analysis were both applied in the study, the HR assessed with multivariate analysis was abstracted. If the PODXL was stained both by polyclonal antibody and monoclonal antibody, the datum of the former were extracted. Any disputes were discussed with the third investigator (Qi X).

\section{Statistical analysis}

Meta-analysis was carried out by Review Manager Version 5.3 software. The prognosis outcomes were assessed using the HR, along with the corresponding 95\% $\mathrm{CI}$ or $p$ values. The prognosis outcomes mainly contained the OS, disease-specific survival (DSS), DFS, cancerspecific survival (CSS), progression-free survival (PFS), time to recurrence (TTR) or RFS. The heterogeneity was assessed by Cochran's Q test and Higgins $\mathrm{I}^{2}$ among included studies. And the heterogeneity should be considered when $p<0.05$ and/or $\mathrm{I}^{2}>50 \%$, and the random-effect model was applied; if not, the fixed-effect model was used. Besides, the funnel plot was conducted to evaluate publication bias by Review Manager Version 5.3 software. The sensitivity analysis was conducted by Stata 12.0 to access the robustness of the results. $p<0.05$ meant the correction was significant.

\section{CONFLICTS OF INTEREST}

The authors have declared no conflicts of interest.

\section{Author contributions}

Study concepts and design: Zhao Y, Wang J, Qi X; Literature search: Zhao X, Cheng S; Data extraction: Qi R, Huang C; Data analysis: Wang S, Zhu X; Manuscript preparation and revision: Zhao Y, Wang J, Qi X. All authors have participated sufficiently in the study and approved the final version.

\section{REFERENCES}

1. Sassetti C, Tangemann K, Singer MS, Kershaw DB, Rosen $\mathrm{SD}$. Identification of podocalyxin-like protein as a high endothelial venule ligand for L-selectin: parallels to CD34. J Exp Med. 1998; 187:1965-75.

2. Kerjaschki D, Sharkey DJ, Farquhar MG. Identification and characterization of podocalyxin--the major sialoprotein of the renal glomerular epithelial cell. J Cell Biol. 1984; 98:1591-6. 
3. Somasiri A, Nielsen JS, Makretsov N, McCoy ML, Prentice L, Gilks CB, Chia SK, Gelmon KA, Kershaw DB, Huntsman DG, McNagny KM, Roskelley CD. Overexpression of the anti-adhesin podocalyxin is an independent predictor of breast cancer progression. Cancer Res. 2004; 64:5068-73.

4. Horvat R, Hovorka A, Dekan G, Poczewski H, Kerjaschki D. Endothelial cell membranes contain podocalyxin--the major sialoprotein of visceral glomerular epithelial cells. J Cell Biol. 1986; 102:484-91.

5. Doyonnas R, Nielsen JS, Chelliah S, Drew E, Hara T, Miyajima A, McNagny KM. Podocalyxin is a CD34-related marker of murine hematopoietic stem cells and embryonic erythroid cells. Blood. 2005; 105:4170-8.

6. Konstantopoulos K, Thomas SN. Cancer cells in transit: the vascular interactions of tumor cells. Annu Rev Biomed Eng. 2009; 11:177-202.

7. Thomas SN, Schnaar RL, Konstantopoulos K. Podocalyxinlike protein is an E-/L-selectin ligand on colon carcinoma cells: comparative biochemical properties of selectin ligands in host and tumor cells. Am J Physiol Cell Physiol. 2009; 296:C505-13.

8. Nielsen JS, McNagny KM. The role of podocalyxin in health and disease. J Am Soc Nephrol. 2009; 20:1669-76.

9. Larsson A, Johansson ME, Wangefjord S, Gaber A, Nodin B, Kucharzewska P, Welinder C, Belting M, Eberhard J, Johnsson A, Uhlen M, Jirstrom K. Overexpression of podocalyxin-like protein is an independent factor of poor prognosis in colorectal cancer. Br J Cancer. 2011; 105:666-72.

10. Larsson A, Fridberg M, Gaber A, Nodin B, Leveen P, Jonsson G, Uhlen M, Birgisson H, Jirstrom K. Validation of podocalyxin-like protein as a biomarker of poor prognosis in colorectal cancer. BMC Cancer. 2012; 12:282.

11. Larsson AH, Lehn S, Wangefjord S, Karnevi E, Kuteeva E, Sundstrom M, Nodin B, Uhlen M, Eberhard J, Birgisson H, Jirstrom K. Significant association and synergistic adverse prognostic effect of podocalyxin-like protein and epidermal growth factor receptor expression in colorectal cancer. $\mathrm{J}$ Transl Med. 2016; 14:128.

12. Kaprio T, Fermer C, Hagstrom J, Mustonen H, Bockelman C, Nilsson O, Haglund C. Podocalyxin is a marker of poor prognosis in colorectal cancer. BMC Cancer. 2014; $14: 493$.

13. Heby M, Elebro J, Nodin B, Jirstrom K, Eberhard J. Prognostic and predictive significance of podocalyxinlike protein expression in pancreatic and periampullary adenocarcinoma. BMC Clin Pathol. 2015; 15:10.

14. Chijiiwa Y, Moriyama T, Ohuchida K, Nabae T, Ohtsuka T, Miyasaka Y, Fujita H, Maeyama R, Manabe T, Abe A,
Mizuuchi Y, Oda Y, Mizumoto K, et al. Overexpression of microRNA-5100 decreases the aggressive phenotype of pancreatic cancer cells by targeting PODXL. Int J Oncol. 2016; 48:1688-700.

15. Saukkonen K, Hagstrom J, Mustonen H, Juuti A, Nordling S, Fermer C, Nilsson O, Seppanen H, Haglund C. Podocalyxin Is a Marker of Poor Prognosis in Pancreatic Ductal Adenocarcinoma. PLoS One. 2015; 10:e129012.

16. Binder ZA, Siu IM, Eberhart CG, Ap Rhys C, Bai RY, Staedtke V, Zhang H, Smoll NR, Piantadosi S, Piccirillo SG, Dimeco F, Weingart JD, Vescovi A, et al. Podocalyxinlike protein is expressed in glioblastoma multiforme stemlike cells and is associated with poor outcome. PLoS One. 2013; 8:e75945.

17. Laitinen A, Bockelman C, Hagstrom J, Kokkola A, Fermer C, Nilsson O, Haglund C. Podocalyxin as a Prognostic Marker in Gastric Cancer. PLoS One. 2015; 10:e145079.

18. Borg D, Hedner C, Nodin B, Larsson A, Johnsson A, Eberhard J, Jirstrom K. Expression of podocalyxin-like protein is an independent prognostic biomarker in resected esophageal and gastric adenocarcinoma. BMC Clin Pathol. 2016; 16:13.

19. Boman K, Larsson AH, Segersten U, Kuteeva E, Johannesson H, Nodin B, Eberhard J, Uhlen M, Malmstrom PU, Jirstrom K. Membranous expression of podocalyxinlike protein is an independent factor of poor prognosis in urothelial bladder cancer. Br J Cancer. 2013; 108:2321-8.

20. Forse CL, Yilmaz YE, Pinnaduwage D, O'Malley FP, Mulligan AM, Bull SB, Andrulis IL. Elevated expression of podocalyxin is associated with lymphatic invasion, basallike phenotype, and clinical outcome in axillary lymph node-negative breast cancer. Breast Cancer Res Treat. 2013; 137:709-19.

21. Flores-Tellez TN, Lopez TV, Vasquez Garzon VR, VillaTrevino S. Co-Expression of Ezrin-CLIC5-Podocalyxin Is Associated with Migration and Invasiveness in Hepatocellular Carcinoma. PLoS One. 2015; 10:e131605.

22. Snyder KA, Hughes MR, Hedberg B, Brandon J, Hernaez DC, Bergqvist P, Cruz F, Po K, Graves ML, Turvey ME, Nielsen JS, Wilkins JA, McColl SR, et al. Podocalyxin enhances breast tumor growth and metastasis and is a target for monoclonal antibody therapy. Breast Cancer Res. 2015; $17: 46$.

23. Lin CW, Sun MS, Liao MY, Chung CH, Chi YH, Chiou LT, Yu J, Lou KL, Wu HC. Podocalyxin-like 1 promotes invadopodia formation and metastasis through activation of Rac1/Cdc42/cortactin signaling in breast cancer cells. Carcinogenesis. 2014; 35:2425-35.

24. Tierney JF, Stewart LA, Ghersi D, Burdett S, Sydes MR. Practical methods for incorporating summary time-to-event data into meta-analysis. Trials. 2007; 8:16. 